\title{
A Framework to Stimulate Collaborative e-Learning through Collaborative Educational Games Modeled Using IMS-LD
}

\author{
Abderrahim El Mhouti \\ Abdelmalek Essaadi University, Faculty of Sciences/LIROSA laboratory, Tetouan, 93000, Morocco \\ E-mail: abderrahim.elmhouti@gmail.com \\ Azeddine Nasseh and Mohamed Erradi \\ Abdelmalek Essaadi University, Ecole Normale Supérieure/LIROSA laboratory, Tetouan, 93000, Morocco
}

\begin{abstract}
In an e-learning environment, learn in a collaborative way is not always so easy because one of the difficulties when arranging e-learning contents can be that these contents and learning paths are not adapted to this type of learning. Online courses are constructed in a way that does not stimulate interaction, cooperation and collaborative learning. This is why the e-learning often is seen as individual and lonely. In this sense, one way to reduce these problems and promote collaborative elearning and interaction learner-learner and learnerteacher is to model these contents in the form of collaborative educational games.

The primary aim of this work is to exploit the potential of educational games to improve students' collaboration in e-learning environments. Thus, this paper presents a framework for designing, implementing and building collaborative educational games targeted to e-learning. The proposed framework is composed of two main phases: game design phase that consists to propose a collaborative design process of educational games; and game development phase that consists to implement, package, describe and deliver the games using the IMSLD standard. The paper describes the steps followed for modeling games, the framework architecture and adopted technical choices. The final framework supports the creation and the use of such games using one of the most popular tools of learning in the web era: the LMS (Learning Management System).
\end{abstract}

Index Terms-Collaborative learning, collaborative educational games, e-learning, learning design, learning object, IMS-LD (Instructional Management SystemsLearning Design), LMS (Leaning Management System).

\section{INTRODUCTION}

Today, e-learning technology offers a wide range of new opportunities for development of education. The advantages of the use of e-learning cover administrative, financial, societal as well as pedagogical areas. The evolution of Web 2.0 technologies and its implications in e-learning allows envisaging new teaching and learning forms, giving a preponderant place to the collaboration, cooperation and social interaction [1].

However, despite their rapid development, the pedagogical potential of Web technologies suffer from the limitations that hinder their development in the distance learning field. Indeed, if e-learning systems have known a great success mainly due to their innovative nature in the way of learning, major problems related to their use are emerging, primarily the quality of the presented educational contents, which are unsuited to collaborative learning context. In this context, many studies have shown that educational content is a misleading indicator of the success of an online learning environment and that this non adequacy is sometimes due to a lack of social learning character of these contents, often linked the problem of individualization of learning [2] [3]. Thus, it is at this level that the Collaborative Educational Games (CEGs) can be used to confront this problem.

In this context, this paper is a contribution to the research efforts in the design of collaborative learning in e-learning environments. The problem posed is how to use the CEGs to offer the learner a collaborative learning experience that is appropriate to his knowledge and his way of learning. Thus, in order to promote collaborative learning, we have reformulated this problem by proposing a reference framework of design, development and use of CEGs by means of reusable and interoperable Learning Objects (LO), while considering the different pedagogical and technical aspects. CEG, produced as LO, are adapted to the IMS-LD (Learning Design) standard. The games design process takes place in an Educational Games Design Environment.

The paper is organized as follows: firstly, the paper highlights the potential of educational games in elearning environments and presents the main characteristics of this concept while at focusing on its collaborative dimension: collaborative educational games. The paper describes the LD stakes, which can be applied in the implementation of CEGs and exposes a literature review of main characteristics of the IMS-LD specification, on which this work is based. The article goes on to describe the main phases of the proposed 
framework and its conceptual structure. Finally, the paper proceeds to describe the technological choices to implement the proposed framework and concludes with future works.

\section{RESEARCH BACKGROUND}

In e-learning, the pedagogical content is the concern of all educational institutions at all their levels. However, several works in practical contexts show that these contents are not adapted to social and collaborative learning vision, vision increasingly favored in e-learning world [3][4][5].

To overcome this problem, this work aims to establish a model of design, development and use of Collaborative Educational Games to stimulate collaborative learning in e-learning environments. Before describing the design and implementation of the proposed framework, this section is oriented towards the presentation of theoretical and methodological basic concepts which we refer in this work.

\section{A. Educational games : an overview}

An educational game is a game designed to teach humans about a specific subject and to teach them a skill. As educators, governments, and parents realize the psychological need and benefits of gaming have on learning, this educational tool has become mainstream. Games are interactive play that teaches us goals, rules, adaptation, problem solving, interaction, all represented as a story. They give us the fundamental needs of learning by providing - enjoyment, passionate involvement, structure, motivation, ego gratification, adrenaline, creativity, social interaction and emotion [6].

Despite the long tradition of games for education and training, the implication of their collaborative dimension in education practices is very limited - especially, when compared to the boost in the games market. The reasons for this are manifold: high technical demands are in conflict with available budgets. Collaborative educational games often do not fit in the educational context or they are hard to tailor. It is hard for teachers to support collaborative educational games within their educational processes [7].

The essential features of an education game are: $1 /$ free action, begun and finished by the user; 2/ imaginary, parallel to the real world, replicating a universe or an activity without any consequence on actual issues; 3/ limited, in time and space; 4/ following a set of rules, a specific and private framework; 5/ with an uncertain solution and development, since every run, every play, is different and depends on unpredictable behavior of users.

For a game, to be an educational one, some additional features are required: $1 /$ it has to start with a problem to be solved; $2 /$ it has to be unproductive itself; it doesn't generate any property or wealth. The drive is the gaming activity itself; $3 /$ it has a correct solution, at least; $4 /$ it should have something to be learnt by the user/player, while introducing new knowledge, fixing previous acquired knowledge, training skills, sharing experiences, discovering new concepts, developing outcomes

Finally, to be an electronic game the educational game must be run on an electronic platform, such as a computer, an online terminal, a video-player, a PDA, a mobile phone etc.

Today, the integration of collaborative educational games in the e-learning environments is becoming a growing need. CEGs have a lot of potential to raise students' collaboration and motivation and improve the quality of education when applied properly. However, the implementation of such games for e-learning is a hard task and development of a new one is expensive. In this sense, several pedagogical and technical aspects must be taken into consideration and the design/development process should be focused on socioconstructivist learning and collaboration skills.

A CEG is a specific type of e-learning content. The design and implementation of these CEG must be done according to the Learning Design (LD) process. As well, to be suited to the collaborative learning context, the LD process of these games must take into account some pedagogical and technical aspects. From the pedagogical point of view, the design of CEG must take into account the collaborative dimension of learning. From the technical point of view, the implementation of CEG using learning objects must take into account pedagogical standards for e-learning, that have changed the way that we exercise the practices of learning design [8]. In the following, we describe the LD stakes, which can be applied in the implementation of CEGs.

\section{Learning Design (LD)}

LD consists to the description of the teaching process following a specific pedagogical approach that addresses specific learning objectives for a particular audience in a particular discipline [9]. Fig. 1 illustrates the relations among the Unit of Learning (UoL: a concept increasingly used in the field of the LD), learning model, domain model, and theories of learning and instruction.

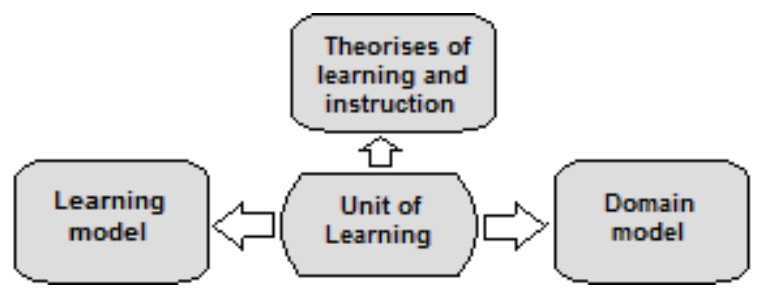

Fig.1. The context of LD

The learning model describes how students learn based on various learning theories. The domain model describes the content and its organization, for example, software engineering or data on the Web. The theories of learning and instruction describe the instruction principles and models based on the literature or the experience of practitioners [10].

In the field of e-learning, to enable the design of the dynamics of teaching and learning and their standardization, the IMS Global Learning Consortium established a new specification for online learning. This 
specification, named IMS Learning Design (IMS-LD), provides a framework of elements that can describe any design of a teaching-learning process in a formal way. In the following, we describe in detail this specification and we will focus on e-learning-based games, since IMS LD is also based on this platform.

\section{IMS-LD}

IMS-LD (Instructional Management Systems-Learning Design) is a pedagogically expressive specification to model Units of Learning (UoL) in a formal, semantic, interoperable and machine-readable fashion. The IMS project aims to establish standards for dealing with problems associated with the increasing use of new technologies in teaching and learning [11].

IMS- LD is a specification to represent and encode learning structures and methods [12]. It supports a wide range of modern pedagogical approaches such as active learning, collaborative learning and adaptive learning [9].

IMS-LD is focused on the design of pedagogical methods able to manage learning activities linked to LO within a learning flow. This learning flow consists of plays, acts, activities, activity structures and environments and it is flexible enough to provide several personalized itineraries depending on the role assigned or on a set of rules. The usual life-cycle starts with a lesson plan modeled according to the IMS-LD, defining roles, learning activities, services and several other elements inside a XML document [13].

IMS-LD is structured in three levels: A, B and C (Fig. 2). With a detailed description of roles, activities, environments, methods (Level A), properties, global elements, monitoring services and conditions (Level B), and notifications (Level C), IMS LD is able to translate regular lesson plans into standardized interoperable UoL.

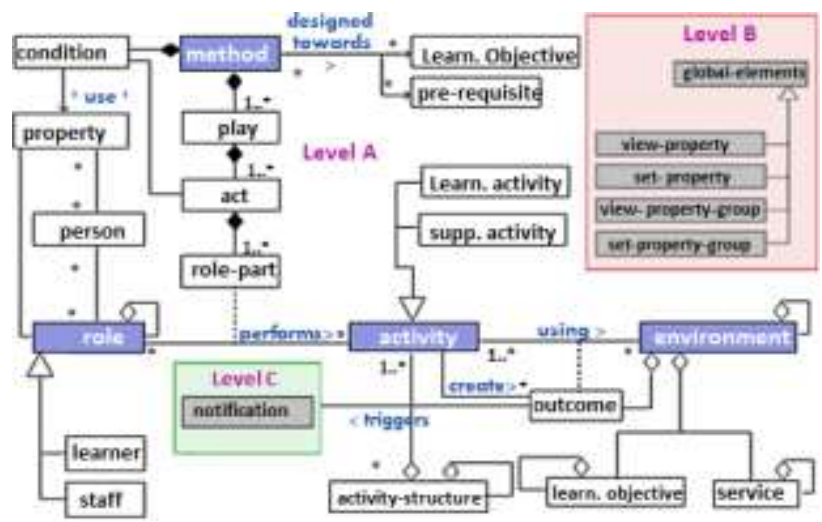

Fig.2. Three levels and information model of the IMS-LD specification
These UoLs can be created with general purpose editors or with specific IMS-LD editors, like CopperAuthor or Reload LD Editor, and they can be run with several tools and engines, like CopperCore or Sled. There is a number of existing runnable example UoLs focused on several educational issues although not too many on games. Furthermore, it has not been tested extensively during the development of IMS-LD whether it could model educational games. IMS LD has several features to suggest that it can be used to do it. Thus, IMSLD can support the representation of CEG in the form of potentially reusable learning objects.

IMS LD's generality implies that it should also be capable of modeling computer-based educational games. Issues on synchronization, grouping, multirole playing, timing, collaborative working, dynamic feedback, adaptive learning and more are implicit or explicit in educational gaming and can be approached with it. Also, a framework must be defined to describe what is considered as an educational game. Many games are described as educational ones yet the educational character of a game depends on the objectives, the context and the moment when it is run [14].

\section{B. Use of educational games in e-learning}

E-learning can be defines as a way of learning which is supported or facilitated by ICT (Information and Communication Technologies). It is a web-based training means by which connections, sharing, support, and access to learning opportunities can be enabled. Ref. [15] consider that there are such wide variations in the conception of this term (along with online learning and distance learning), that defining the characteristics of each is almost impossible.

This web-based training model gradually evolved. Today, e-learning is a very popular phenomenon and forms the core of a number of initiatives and programs offered by colleges and universities [16].

Web 2.0 has given birth to e-learning 2.0. The influence of new practices on the Web has resulted in a new array of services, which can be collectively termed "e-learning 2.0" (Fig. 3).

E-learning 2.0 refers to a second phase of e-learning based on Web 2.0 and emerging trends in e-learning such as the collaborative e-learning. It is based on creating and sharing information and knowledge with others using social media tools like blogs, wikis, social bookmarking and social networks within an educational context to support collaborative approach to learning [16].

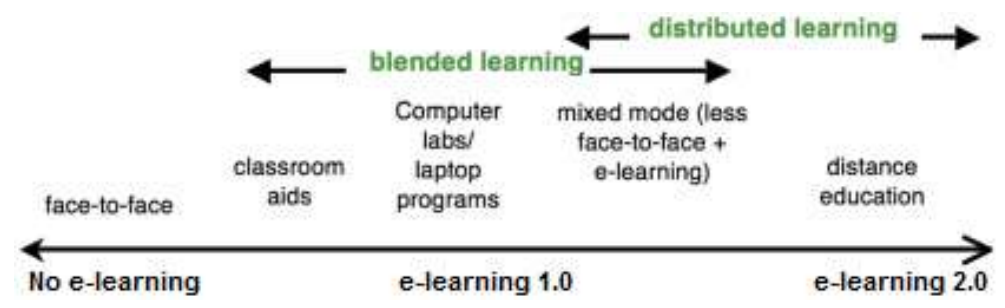

Fig.3. Different forms of e-learning [17] 
Educational games are becoming popular in the academic discussion of learning technologies, in particular e-learning. In an e-learning environment, educational games provide the motivation and engagement of learner and can keep people of different conditions focused and concentrated on a task during long periods of time. Educational games are designed to offer learners the opportunity to develop their skills and knowledge in a meaningful and practical, yet virtual, training setting. They carefully balance fun, knowledge transfer, and reality to provide the trainee a meaningful, immersive, and motivating learning experience, facilitated by the Web 2.0 tools offered (social networking, wikis, blogs, ...).

On the other hand, educational games are usually one of the most resource-consuming products of the software industry. As a proof of this claim, the educational games industry is pointed out because of the key role it plays in the promotion of learning technology (both hardware and software). This fact, along with the inherently high development cost of educational games forces developers to follow a design strategy in which runtime performance is a key aspect. Hence, educational games are usually closed products, difficult to deploy in heterogeneous elearning environments, and hardly ever designed to be deployed directly from the web. That makes their integration in current e-learning environments, particularly the LMS (Learning Management Systems), a big challenge. Considering this, it is mandatory to find solutions for the development of educational games that can be easily integrated and used in e-learning environments, and that follow the current trends in standardization [18].

\section{Collaborative Educational Games: a way to promote collaborative e-learning}

Collaborative e-learning systems are cyberspaces in which individual and collaborative learning is implemented by groups of geographically dispersed learners and providers of knowledge to accomplish their goals of learning. Important aims of the courses in these environments have been that student should learn from each other and share knowledge [19]. In these e-learning environments, knowledge (pedagogical content) is based on social entities and is the key to their success.

An important activity in a collaborative e-learning environments is the collaboration between learners. Collaborative learning is a learning approach characterized by participation and interactivity for both students and teachers and involving joint intellectual effort by students, or students and teachers together. Usually, students are working in groups of two or more, mutually searching for understanding, solutions, or meanings, or creating a product.

Many collaborative e-learning systems strive to attract new members or encourage members to learn collaboratively. Nevertheless, such collaboration environment is generally not supported by conventional learning environments, way that does not stimulate interaction, collaboration and cooperation [20].

\section{A FRAMEWORK FOR IMPLEMENTING COLLABORATIVE EDUCATIONAL GAMES BASED ON IMS-LD}

In e-learning environments, learn in a collaborative way is not always so easy because one of the difficulties when arranging e-learning contents can be that these contents and learning paths are not adapted to this type of learning. Even when trying to solve this by correctly assuming the practices of learning design we are not always able to avoid these problems if we ignore the collaborative dimension of learning in the design process. However, one way to reduce these problems and promote collaborative e-learning and interaction learner-learner and learner-teacher is to model these contents in the form of Collaborative Educational Games.

For that purpose, we propose a simple methodology for the design and development of collaborative educational games targeted to e-learning and composed of two steps: games design step that consists to propose a collaborative design process of educational games; and game development step that consists to implement, package, describe and deliver the games using the same standards and specifications that are currently being used in those elearning environments, especially the IMS-LD standard.

In this section, we will define and explain the foundations on which rests the implementation of the framework of Learning Design based on IMS-LD to develop collaborative educational games and we continue by describing its conceptual architecture and technical choices adopted to implement it.

\section{A. Online and Collaborative Learning Design model}

\section{Description}

The proposed Learning Design process of collaborative educational games is similar to what we find in the software engineering. The process is assured according to a life cycle adapted, following to an incremental process broken down into several phases which correspond to a set of tasks to perform collaboratively. The use of a life cycle brings several advantages: promotes traceability, improves the visibility on the content evolution and promotes the constitution of groups [21].

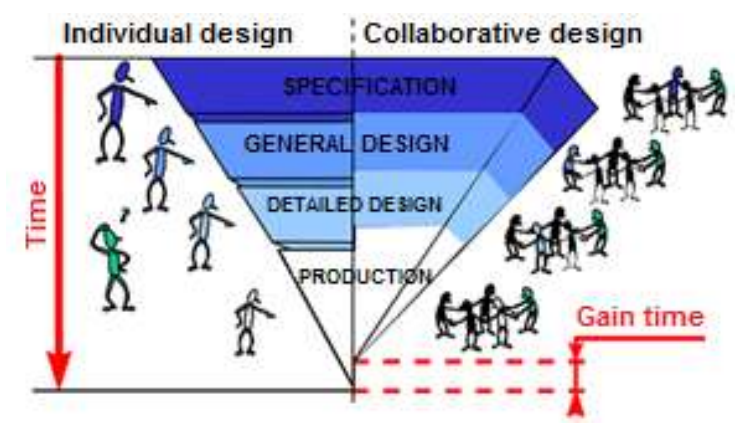

Fig.4. Collaborative design process of educational games

Considering its advantages, the choice fell on the model known as "V-Cycle". The strong point of this model is that any description of a pedagogical component is accompanied by tests, which will ensure that it matches 
its initial description. Fig. 4 illustrates the steps of the design process of collaborative educational games.

Note also that in the proposed model, the proposed design process of collaborative educational games.is done collaboratively and not individually. In this sense, the first advantage of adopting collaborative design to implement collaborative educational games will thus reducing the time and therefore costs of development of such educational games. Besides the advantages mentioned above, in the proposed learning design method the actors involved in the different stages work together. They are moving towards a partial parallelism throughout this process.

2. Structuring and modeling educational games with IMS-LD

In the proposed structure, the educational game is hierarchical to tree whose root is the learning unit (educational game) and branches are composed of Sequences and Acts concepts. Each level has properties and this is the most suitable structure to represent the educational game, taking into account the indexing and reuse criteria. Fig. 5 shows the structure adopted for representing a collaborative educational games.

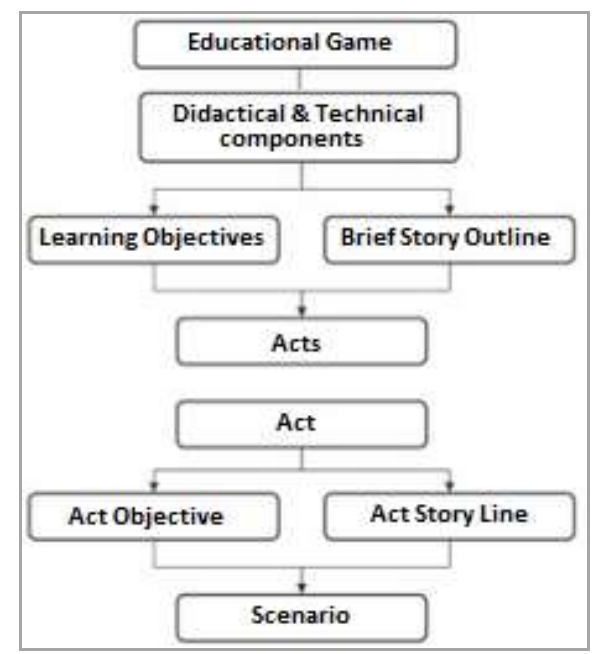

Fig.5. Structure of educational games
Collaborative educational games can be easily modeled with IMS Learning Design standard because this standard borrows the theater metaphor to model a teachinglearning process. The method part is where the top-level coordination of people and activities takes place. A play, as in a theatrical play, consists of acts, although there can be one-act plays. Acts run in sequence, with one starting when the previous act has finished, and the collaborative educational game ends with the completion of the last act.

The transition from one act to another serves as a synchronization point for the multiple participants in a learning design, ensuring that they can all start the next act at the same time. An act is composed of activity, activity structure, and role-part. In every act, the role-part associates a role with an activity (Fig. 6).

An activity is the basic learning unit and references to a physical learning material. It usually links to contents including plain text, hypertext, graphics, streaming media, and so on. This binding is accomplished through the environment tag for the sake of reusability. In the next section, we describe the main phases of the framework of design and implementation of collaborative educational games.

\section{B. Main phases}

In the framework of design and implementation of Collaborative Educational Games, the proposed process is composed of three main steps: educational game design, educational game production and educational game diffusion. In each step, a graphical interface and a set of tools used to complete the corresponding task: pedagogical task, didactic task, mediatic task and technological task. Fig. 7 shows the process of generating of the collaborative educational game packaged as a learning object.

The educational game design phase takes place in an online space called "Educational Game Design Environment". In this space, teachers authors develop a structured and hierarchical representation of concepts and knowledge to teach and model the learning paths, scenarios and possible sequences.

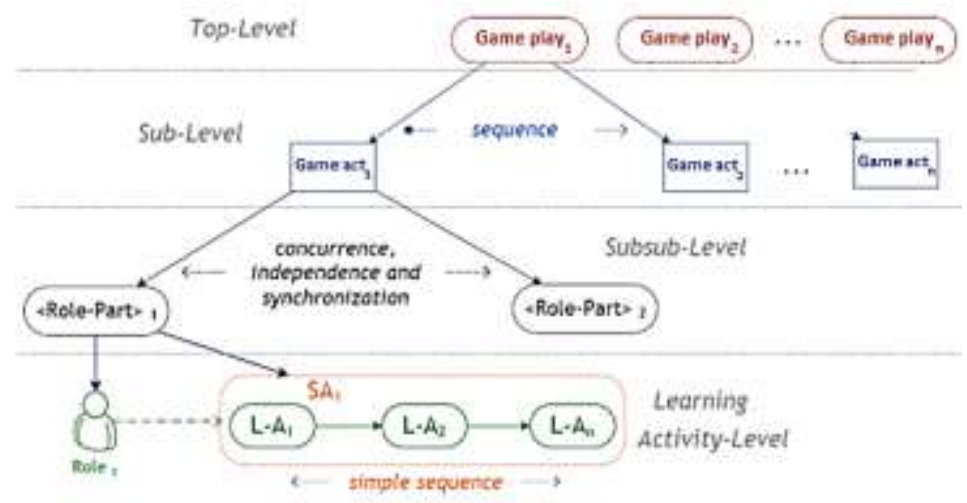

Fig.6. Nested structure of learning activities of educational game 


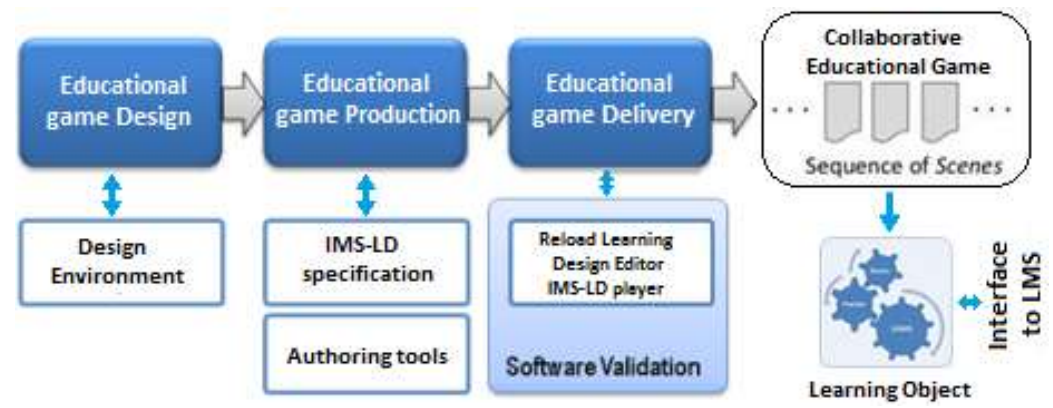

Fig.7. Collaborative educational games design process phases

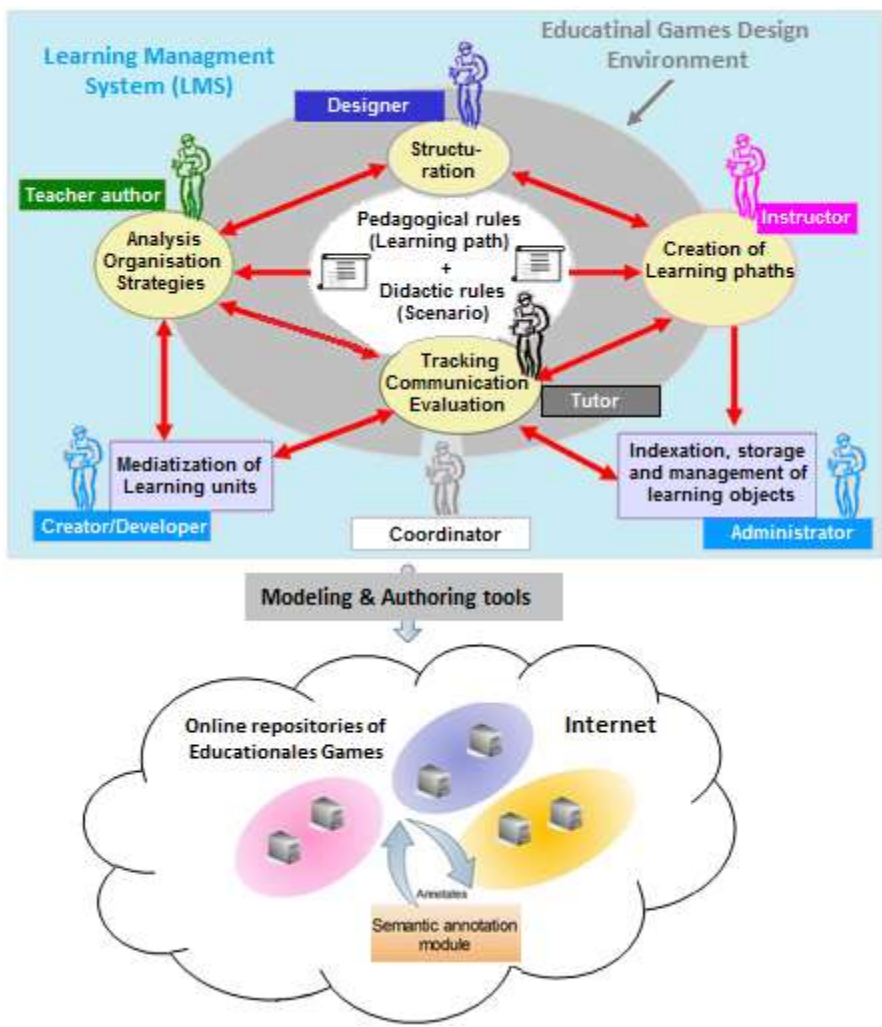

Fig.8. Architecture of the proposed model

The game production phase concerns the mediatization of learning paths and scenarios developed in the previous step. Here, the units of learning (educational games) are produced according to IMS-LD format. To facilitate this task, it was proposed to use the authoring tools to create the collaborative educational game. Teachers authors consult a resources management system to select a mediatic object (image, video, animation, file, etc.). Each selected mediatic object is associated with one or more acts.

The last phase of this process is that of educational game delivery as standard learning objects. In this phase, it was proposed to use the authoring called Reload Learning Design Editor. It is a scenario development tool to generate the executable version of the learning object compatible to IMS-LD format to ensure reusability and interoperability. Thus, it is possible to package the educational games according to the IMS-LD specification and annotated with meta-data. The result is a shareable and reusable collaborative educational game packed as an learning object and ready to be deployed in any IMScompliant LMS.

\section{Conceptual structure}

The general architecture of the proposed framework of design and implementation of Collaborative Educational Games is based on two complementary parts: 1/ design part, which is done in collaboration between the various actors according to the $\mathrm{V}$ life cycle; and $2 /$ development part, to create games as learning objects compatible with IMS-LD format. Fig. 8 illustrates the general architecture of the proposed framework.

In this architecture, we can distinguish two tasks performed by the staff of authors/designers (authorsteacher, designer, developer, coordinator, etc.):

- Game design task: this task concerns two roles carried out by members of the staff according to their specialty: pedagogical role and didactic role.

- Game development task: this task also concerns 
two functions exercised by the members of the staff: technical role and mediatic role.

The game design task takes place in the Educational Games Design Environment. This space aims at making available to teachers an environment which allows many possibilities. This is an LMS providing two main functions. Through this space, collaborative design is facilitated by exchange and sharing of information, participation in forums, use of videoconference and other tools of synchronous/asynchronous communication. This area is also responsible for everything related to management: it manages the educational games and educational resources, authors profiles, registration, etc.

After the design of the educational game, the staff starts game development task. Among many standards analyzed, the IMS-LD was used to describe the main elements of the educational game design process. We have adopted this standard for modeling UoL because, currently, it represents the most popular formal language to describe learning designs. It is a formal pedagogical standard to describe technology supported pedagogical scenarios based on rich instructional design models.

At the end of the game design and development process, author creates the executable version of the learning object produced and stores them in online repositories in order to annotate them. This task is done using the authoring tool Reload Learning Design Editor (RLDE). It should be noted also that it is a modeling using the adaptive level of IMS-LD (level A).

The RLDE is an Open Source, close-to-specification, tree-based Learning Design editor written in Java using the Eclipse platform. The editor tools are complemented by a LD Player, which provides a familiar and userfriendly interface to the CopperCore LD runtime engine [22]. The RLDE workspace is shown in Fig. 9 below.

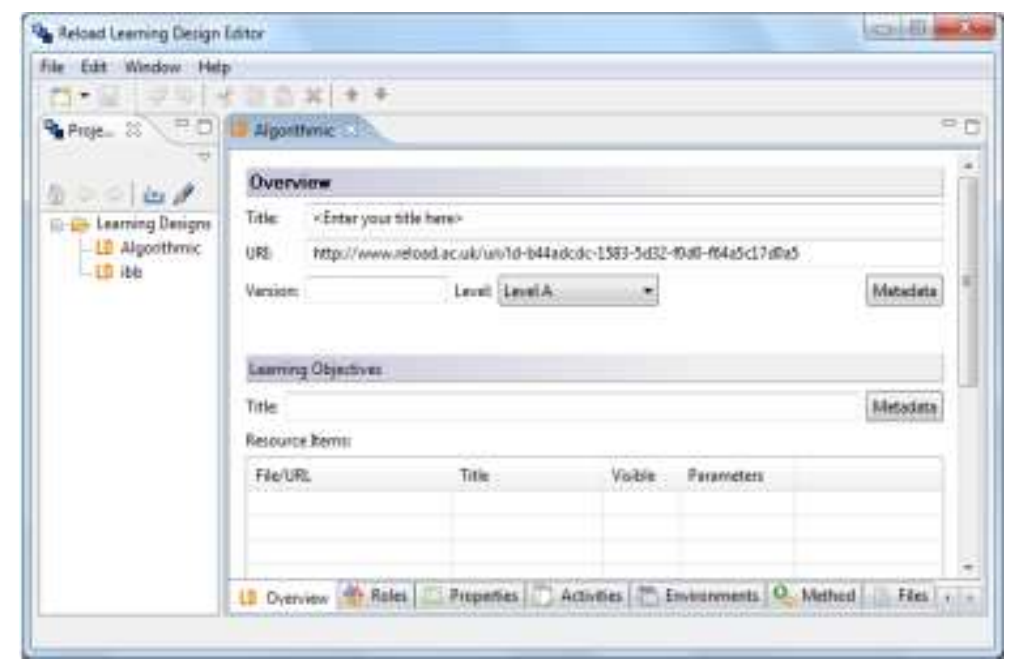

Fig.9. The Reload Learning Design Editor Workspace

RLDE is an editor providing a series of forms for completion, based on a structure closely resembling the data model in the IMS-LD specification. The user starts off with an empty Learning Design and adds the relevant elements as required. The tools structure the learning design by only allowing valid structures.

\section{Implementation}

An effective mechanism to distribute the games to the learners would be to deliver them through a LMS. Delivering a game through a LMS is more effective than other approaches. Additionally, the tracking and assessment features of some modern LMS would give the instructor more power to control aspects of the learning experience such as when the students accessed the game, the time each student spent playing it and the outcomes of the game session.

In this sense, to implement the proposed framework of design and implementation of Collaborative Educational Games, the choice of technologies is based on the reuse and the linking of many existing software solutions. Thus, we have setting up an LMS ensures two main functions: integrates the Educational Games Design Environment and manages resources, courses, users accounts, etc. In addition, this LMS offers a learning environment to distribute the games to the learners. After comparative studies conducted, the platform used is the LMS Dokeos (version 2.1). It is an LMS developed in PHP and built around a client-server architecture.

Dokeos has been devised for the distribution of online courses that are mainly based on web contents that are packaged and distributed according to a set of standards and specifications. However, the IMS-LD specification is not supported by Dokeos. That's why we have oriented our work towards the management and exploitation of educational content by implementing an export and import mechanism in IMS-LD format by adding to Dokeos an runtime environment of learning objects compatible with this format.

Indeed, in Dokeos, services are implemented as 'modules' (such as documents, chat, forum, quiz). Instances of modules are inserted within sections that form the course structure. Hence, resources for learning can be arranged to organize the teaching-learning process 
according to predefined course formats. Functions for course formats are implemented separately from functions for modules. This offers the possibility to create new course formats for Dokeos. Thus, a new course format was implemented in this LMS. This new course format provides functions to use Dokeos as a runtime environment for educational games compliant to IMS-LD level A. In this course format, resources for learning can be arranged according to the core concepts of IMS-LD. The required course structure is described in the file imsmanifest.xml, which is conformant to XML-schemas for IMS-LD level A. Fig. 10 shows the resulting architecture for the extension of Dokeos to support IMSLD format, with extended components marked in grey.

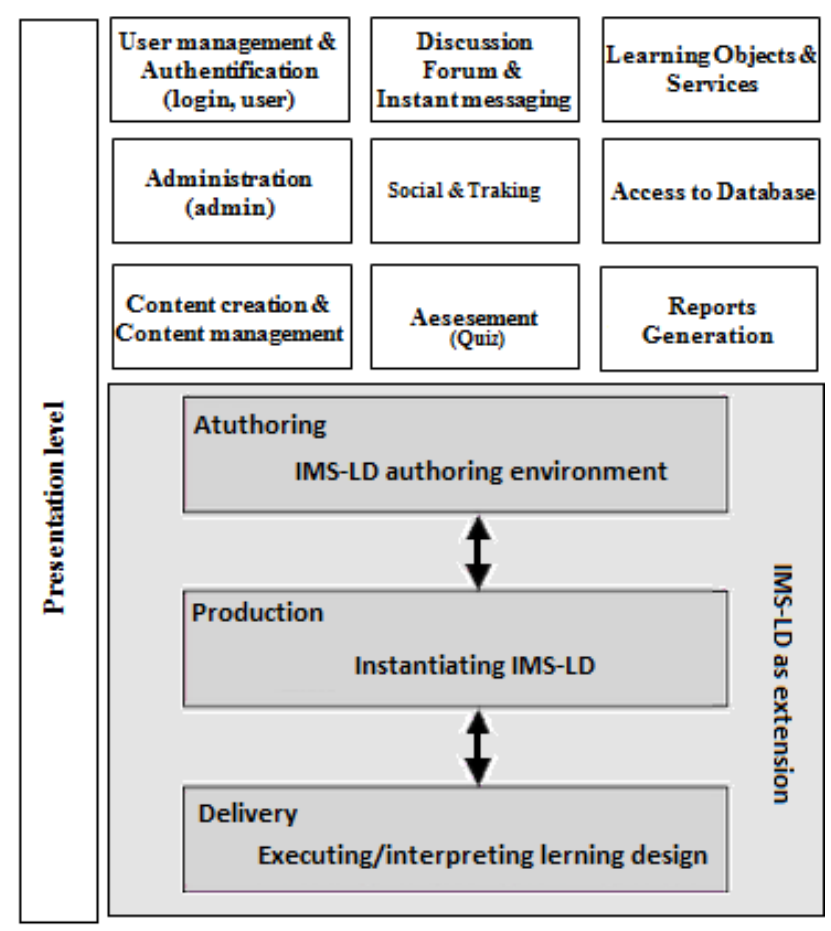

Fig. 10. The prototypical IMS-LD runtime environment integrated in Dokeos platform

The graphical user interface of the web-based learning environment of Dokeos offers different views of the educational game structure, depending on role, progress in the teaching-learning process and user's choice. For these views, the information in the file imsmanifest.xml for a running educational game is processed (on the server side through XSL transformations and access to the XML-DOM) and presented to both learners and teaching staff.

\section{CONCLUSION}

In e-learning environments, the purpose for which this type of learning was created cannot be ignored: the collaboration between learners without constraints of time and place. This aspect of collaboration is usually difficult to be achieved because the educational contents presented do not bring anything particular to learners to promote collaborative learning.

The work presented in this paper aims to exploit the potential benefits of collaborative educational games in order to promote and stimulate collaborative learning in e-learning environments. For that, we have presented a general framework for designing and implementing Collaborative Educational Games based on IMS-LD specification. The objective is to provide design support for teachers-authors and instructors to stimulate collaborative learning in e-learning platforms.

The proposed process is composed of two main steps: educational games design step that consists to propose a collaborative design process of educational games ; and educational games development step that consists to implement, package, describe and deliver the games using the IMS-LD standard.

The educational game design process, which takes place in an online collaborative design environment, is ensured following the $\mathrm{V}$ life cycle that we have adapted to the design of educational games. A novel aspect of this approach is that the collaborative learning design process is becoming less the product of a single author, but this is a team work, consists of a manager who ensures the educational coordination and several teachers-authors who design educational games. The authors, freed from the constraints of time and place, must work together, pool their efforts and exchange relevant data. The modeling of educational games as units of learning is done using the Reload Learning Design Editor authoring tool to facilitate the generation of learning objects reusable, interoperable and compatible to IMS-LD format.

As part of the continuity of this work, the proposed framework should be complemented with the proposal of more fine-grained packaging and annotation mechanisms for collaborative educational games, which should facilitate the actual integration of the games into units of learning compatible to IMS-LD format. In addition, we have planned to work on the extension of the model to include the concepts of the levels B and C of the IMS-LD specification.

\section{REFERENCES}

[1] C. Dalsgaard, "Pedagogical quality in e-learning". ELEED, Iss. 1. (urn:nbn:de:0009-5-785), 2005.

[2] F. Trillaud, "Architecture pour le contrôle des interactions et le pilotage d'une application interactive multiutilisateurs à exécution adaptative : application à un environnement de FOAD", Doctoral dissertation, University of La Rochelle, France, 2013.

[3] A. El Mhouti, A. Nasseh and M. Erradi, "An Evaluation Model of Digital Educational Resources", International Journal of Emerging Technologies in Learning, vol. 8, issue 2, pp. 29-35, 2013.

[4] A. El Mhouti, A. Nasseh and M. Erradi, "Design and implementation of a Socioconstructivist Model of Collaborative Learning Design (SMC-LD) dedicated to distance learning", International Journal of Computer Sciences and Engineering, vol. 2, issue 8, pp. 1-10, 2014.

[5] L. Cormier, "Le soutien au développement de ressources numériques pour l'enseignement et l'apprentissage dans les universités québécoises", In proceedings of the 80ème Congrès de l'ACFAS, 2012.

[6] M. Prensky, "Fun, Play and Games: What Makes Games Engaging." Digital Game-Based Learning. McGraw-Hill, 
2001. 30 Jan. 2011.

[7] R. Klemke, M. Kravcik, "Open 3D Environments for Competitive and Collaborative Educational Games", in the Proceedings of the $1^{\text {st }}$ International Workshop on Pedagogically driven Serious Games (PDSG 2012), aarbrücken (Germany), 18th September, 2012.

[8] D. A. Wiley, "Connecting learning objects to Instructional design theory: a definition, a methaphor, and taxonomy". In Wiley (Ed), The Instructional Use of Learning Objects. Agency for Instructional Technology and Association for Educational Communications of Technology, Bloomington, Indiana, 2002.

[9] R. Koper, and B. Olivier, "Representing the learning design of units of learning", Educational Technology \& Society, vol. 7, issue (3, pp. 97-111, 2004.

[10] R. Koper, and Y. Miao, "Using the IMS LD standard to describe learning designs". In: Lockyer, L., Bennet, S., Agostinho, S. and Harper, B. (Eds.), Handbook of Research on Learning Design and Learning Objects Issues, Applications and Technologies. IGI Global, Hersey, pp. 41-86, 2008.

[11] Z. Shariat, S. M. Hashemi, A. Mohammadi, "Researchand Compare Standards of E-Learning Management System: A Survey", International Journal of Information Technology and Computer Science, vol. 6, no. 2, January 2014.

[12] (IMS-LD, 2003) IMSLD: "IMS Learning Design" (2003), Available http://www.imsglobal.org/learningdesign/index.cfm, visited September 14, 2015.

[13] D. Burgos, C. Tattersall, M. Dougiamas, H. Vogten, and R. Koper, "A First Step Mapping IMS Learning Design and Moodle". Journal of Universal Computer Science, vol. 13, issue 7, pp. 924-931, 2007.

[14] D. Burgos, C. Tattersall, and R. Koper, "Can IMS Learning Design be used to model computer-based educational games?” BINARIA Magazine. Issue 5. 2006. Madrid: European University of Madrid.

[15] J. L. Moore, C. Dickson-Deane and K. Galyen, "eLearning, online learning, and distance learning environments: Are they the same?" Internet and Higher Education, vol. 14, pp. 129-135, 2011.

[16] K. A. Rupesh, "E-Learning 2.0: Learning Redefined", Library Philosophy and Practice, ISSN 1522-0222, 2009.

[17] T. Bates, "Understanding Web 2.0 and its Implications for e-learning", Web 2.0 Based e-learning : Appliying Social Informatics for Tertiary Teaching, pp. 21-42, 2011.

[18] J. Torrente, P. Moreno-Ger, I. Martínez-Ortiz, and B. Fernandez-Manjon, "Integration and Deployment of Educational Games in e-Learning Environments: The Learning Object Model Meets Educational Gaming". Educational Technology \& Society, vol. 12, issue 4, pp. 359-371, 2009.

[19] K. L. Anne, and O. H. Grete, "Collaborative learning in elearning", Virtual book e-pedagogy for teachers in higher education, Bergen University College, Bergen, Norway, 2009.

[20] H. Hage, and E. Aïmeur, "Harnessing learner's collective intelligence: A Web2.0 approach to e-learning", Lecture Notes in Computer Science, 5091, pp. 438-447, 2008.

[21] O. Catteau, and P. Vidal, "Le Cycle de Vie de l'Objet Pédagogique et de ses Métadonnées", Doctoral dissertation, Paul Sabatier University, France, 2008.

[22] C. D. Milligan, P. Beauvoir, and P. Sharples, "The Reload Learning Design Tools". Journal of Interactive Media in Education, vol. 06, 2005

\section{Authors' Profiles}

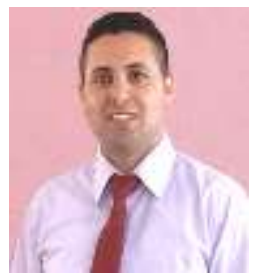

Abderrahim EL MHOUTI - received the $\mathrm{PhD}$ degree in Computer Science in 2015 in LIROSA laboratory and the Master degree in Software Quality in 2011 from Abdelmalek Essaadi University, Faculty of Sciences, Tetouan, Morocco.

Dr. EL MHOUTI is a Professor of Computer Science at the secondary cycle since 2006. His research fields include: collaborative e-learning and pedagogy, Web 2.0 technologies and cloud computing. He has published several articles on e-learning, Web 2.0 and educational technologies.

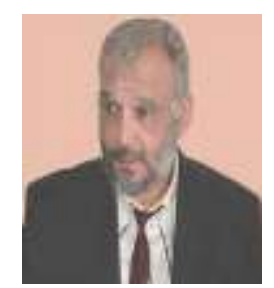

Azeddine NASSEH - received the PhD degree from the Free University of Brussels in Belgium. He is Professor and computer science researcher. $\mathrm{He}$ is member of LIROSA laboratory. His areas of interest include: e-learning and pedagogy, MOOCs, and Web 2.0.

Prof. NASSEH is currently a full Professor of computer science and head of Management and Computer Science Department at Ecole Normale Supérieure, Abdelmalek Essaadi University, Tetouan, Morocco. He has published several articles on E-learning and Web 2.0.

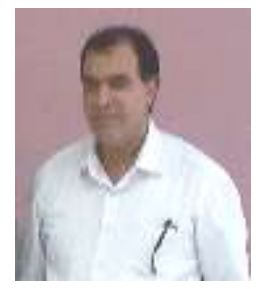

Mohamed ERRADI - received the PhD degree from the Mohammed V University in Morocco. He is Professor and computer science \& pedagogy researcher. $\mathrm{He}$ is member of LIROSA laboratory. His research fields are: e-learning, pedagogy, and educational technologies.

Prof. ERRADI is currently Professor and pedagogy trainer at Ecole Normale Supérieure, Abdelmalek Essaadi University, Tetouan, Morocco. He has published several articles on e-learning and educational technologies.

How to cite this paper: Abderrahim El Mhouti, Azeddine Nasseh, Mohamed Erradi,"A Framework to Stimulate Collaborative e-Learning through Collaborative Educational Games Modeled Using IMS-LD", International Journal of Information Technology and Computer Science(IJITCS), Vol.8, No.4, pp.19-27, 2016. DOI: 10.5815/ijitcs.2016.04.03 